ISSN 1112-9867

\title{
PREPARATION OF ACTIVATED CARBON FROM TAMARIND SEEDS AND METHYLENE BLUE (MB) REMOVAL
}

\author{
N. A. Jamion ${ }^{*}$ and I. N. Hashim \\ Faculty of Applied Sciences, UniversitiTeknologi MARA, Kuala Pilah, Negeri Sembilan, \\ Malaysia
}

Published online: 10 November 2017

\begin{abstract}
In this study, thedye treatment which is methylene blue (MB) as water pollutants was ascertained with the activated carbon that prepared from the tamarind seed (Tamarindusindica). The conditions used to prepare activated carbon, (TSC) were activated using phosphoric acid as an activating agent at temperature $500{ }^{\circ} \mathrm{C}$ for four hours. These conditions may be attributed to enhance the surface area and pores development of TSC. Single point BET surface area $\left(\mathrm{S}_{\mathrm{BET}}\right)$ analysis gave the surface area of TSC was $594.04 \mathrm{~m}^{2} \mathrm{~g}^{-1}$ and FESEM analysis showed that the pores development and formation were mostly in circle and oval pattern. The best conditions for TSC sample to adsorb MB effectively were at $50 \mathrm{~mL}$ of MB with concentration $120 \mathrm{ppm}$ at temperature, $323 \mathrm{~K}$ by using $0.04 \mathrm{~g}$ of TSC. The maximum adsorption capacity for MB dye solution was $102.77 \mathrm{mg} \mathrm{g}^{-1}$.
\end{abstract}

Keywords: Tamarind seed; dyes; methylene blue; adsorption; phosphoric acid.

Author Correspondence, e-mail: ainjamion@gmail.com.my

doi: http://dx.doi.org/10.4314/jfas.v9i6s.9 


\section{INTRODUCTION}

Generally, wastewater from textile industry consists of pigments, various organic and inorganic compounds and dyes. These compounds mostly have an excellent stability to light, oxidizing agents and defiance to the aerobic ingestion which are difficult to degrade due to a complex molecular structure [1]. These characteristics make the compounds become more stable and can remain in the environment for an extended period which is difficult to degrade. Besides that, it also increases the chemical oxygen demand (COD) concentration, a large amount of the suspended solid, fluctuating of the $\mathrm{pH}$, strong colour, toxic and high temperature that harm the aquatic life which have been proven in many research studies [2].

Batik industries are one of the Malaysian cottage textile industries among the rapidly growing textile industries in Malaysia which are commonly found in east coast, Terengganu and Kelantan [3]. Batik industries also lead to a biggest grant to the growth of the Malaysian economy due to increasing number of order from the Malaysian and foreign country. Textile dyeing industries in Malaysia was important and was ranked as the first in the colouration of fiber [4]. Wastewater from the textile industries was declared as one of the major sources of wastewater pollutions in ASEAN countries, after considering both volumes discharge and effluent composition [5].

Dyes are widely used in the industries for example, food colouring, cosmetic, printing, textile dyeing, plastics and leather [6]. Dyes may be classified into a few characteristic which are based on the colour, method of application source and structure. Over around $7 \times 10^{5}$ tonnes per year that has been produced and commercialized, with the textile industry individually discharging more than $1.5 \times 10^{8} \mathrm{~m}^{3}$ of coloured effluents yearly like methylene blue, malachite green, lucidin and others [3].

Basically, there are three general ways that can be applied by the industries to remove the dyes which are biological, chemical and physical methods. In this study, the physical method that was applied is adsorption. The study on the adsorption has been proven that it was an efficient and economical process for the removal of air, water, and soil pollutants (adsorbate) such as heavy metals, surfactants and dyes from various adsorbents. The adsorbent can be prepared from low cost materials; activated natural materials and charcoal are prepared from different type of natural resources like leaves, roots and peel that are usually categorized as agricultural 
waste [7].

Nevertheless, the use of the non-renewable and relatively expensive starting materials like coal, petroleum and tar [8] to prepare commercial activated carbon is considered pricey. Therefore, many researchers find alternative adsorbents that are lower in cost and comparably effective as the commercial activated carbon from agriculture waste. The examples of the agriculture waste are the palm kernel [9], tamarind seed [10] and rubber seed sawdust [11].

Tamarind is known as one of the spice condiments that are widely used in every South-Asian kitchen which is usually sweet and tangy. The scientific name of tamarind is Tamarindusindicawhich belongs to a certain family of Fabaceaein the genus of Tamarindus[12]. Fig. 1 shows the picture of the tamarind seeds and pods. Tamarind fruit comprises certain health benefits that are needed to human like volatile organic compounds, vitamins and fiber. Meanwhile, for the tamarind pods, it has been used as traditional medical treatment for laxative, digestive and as a remedy for biliousness and bile disorder. Tamarind seeds are usually categorized as agriculture waste because of lack of awareness on its benefits and the application of tamarind seed in treat pollutants, especially dyes by adsorption process in Malaysia is still not widely known [13].

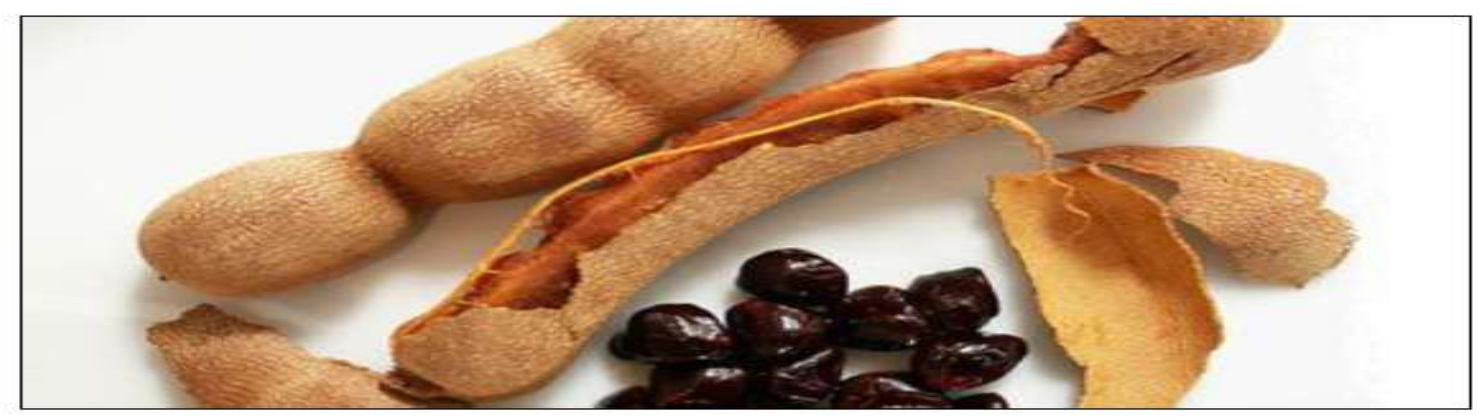

Fig.1.Tamarind seeds and pods.

Therefore, in this study, tamarind seeds were used to prepare the activated carbon to remove methylene blue in the wastewater. Hence, the tamarind seed can be used as activated carbon sources to treat water pollutions which are cheaper, beneficial towards environment and easy to be planted in any type of soils.

\section{RESULTS AND DISCUSSION}

\subsection{Characterization of TSC Activated Carbon}




\subsubsection{Fourier Transformed Infrared Spectroscopy (FTIR)}

The FTIR spectra of the tamarind seed that was analyzed in the range of $400 \mathrm{~cm}^{-1}$ to 4000 $\mathrm{cm}^{-1}$ to find the information about the presence of the functional groups on the tamarind seeds' surface. The spectra obtained were shown in Fig. 2. In the spectrum of the raw tamarind seed (TS), absorption bonds of four functional groups were observed. The broad absorption band appeared at $3319 \mathrm{~cm}^{-1}$ was assigned to the presence of hydroxyl group $(\mathrm{O}-\mathrm{H})$ in the tamarind seed. The second functional group which was $\mathrm{C}-\mathrm{H}$ alkane absorption bands were observed to appear at $2944 \mathrm{~cm}^{-1}, 2831 \mathrm{~cm}^{-1}$ and $1446 \mathrm{~cm}^{-1}$. This indicates that the presence of carbon and hydrogen atoms in the TS. The absorption band appears at $1024 \mathrm{~cm}^{-1}$ was indicated the presence of oxygen in the TS sample. It shows that maybe in TS consist of carbonyl group (C-O). In the spectrum pre-treatment with $30 \%$ of phosphoric acid (PTS) showed a small peak of absorption band at $1631 \mathrm{~cm}^{-1}$ was assigned as a $\mathrm{C}=\mathrm{C}$ stretching, while at $992 \mathrm{~cm}^{-1}$ was associated with stretching vibrations of P-O bonds. By comparing the spectra of PTS with the TS, it shows that the $\mathrm{O}-\mathrm{H}$ bond disappeared after the pre-treatment with $30 \%$ of $\mathrm{H}_{3} \mathrm{PO}_{4}$ and a new P-O bond stretching appeared. This absorbance maybe was come from phosphoric acid $\left(\mathrm{H}_{3} \mathrm{PO}_{4}\right)$. Phosphoric acid is said to act as a dehydrating agent during the pre-treatment and impregnation processes [14]. However, the spectrum of TSC and commercial activated carbon (CAC) did not show any absorbance band. There is no functional groups presence in TSC sample as same as CAC. Thus, from FTIR results, it can be concluded that most organic compounds and functional groups in raw tamarind seed were disappeared after the activation process at $500{ }^{\circ} \mathrm{C}$ for four hours. The absence of functional groups on the TSC activated carbon sample may lead to a better adsorption process and follow the adsorption affinity rules [15], and it can be assumed that TSC will also have the capacity to be used as an adsorbent like CAC. 


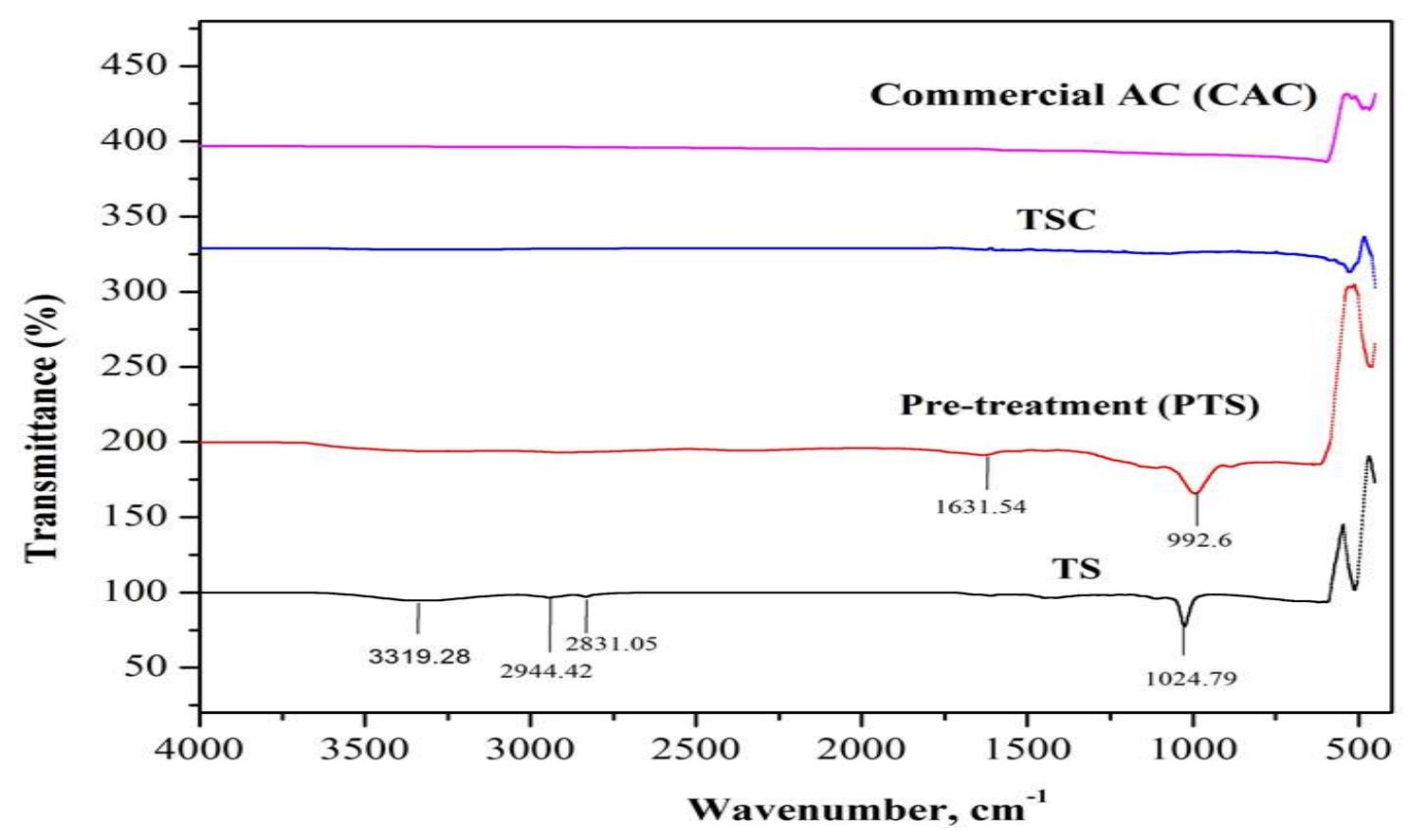

Fig.2. FTIR spectra of commercial AC (CAC), TSC, PTS and TS

\subsubsection{Field Emission Scanning Electron Microscopy (FESEM)}

Surface morphology and porosity of TSC were analysed from the FESEM micrographs. The micrographs of the prepared activated carbon, TSC with different magnification of $35 \mathrm{x}, 500 \mathrm{x}$, and $1.5 \mathrm{Kx}$ are shown in Fig. 3 (a), (b) and (c) respectively. Micrograph (a) with the magnification $35 \mathrm{x}$ showed the pores were uniformly distributed and well developed all around the surface of the TSC sample. It was clearly seen that the pores development and formation were mostly in circle and oval patterns. The enlargement micrographs shown in (b) and (c) found the average pores diameter was in the range of $2 \mu \mathrm{m}$ to $450 \mu \mathrm{m}$. It indicates that the developed pores were mostly macropores. It was also observed that there are holes and cave type opening on the surface of the sample. This might be because of the activation process, the use of phosphoric acid as activating agent, which helped the pores development thus indirectly increased the surface area obtained [16]. This is supported by the Nitrogen Gas Adsorption Single Point Analysis results where the surface area of the TSC obtained was higher compared to the tamarind seed activated carbon prepared with base activating agent $(\mathrm{KOH})[17]$. 


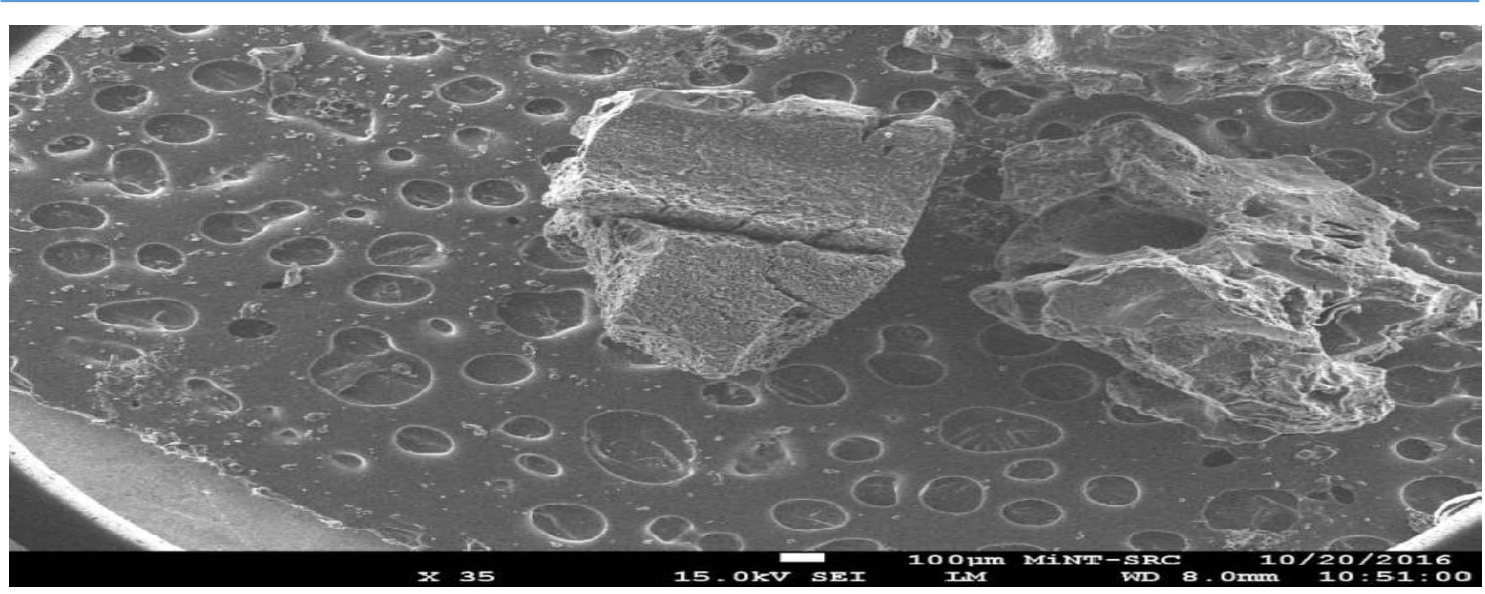

(a) Magnification $35 \mathrm{x}$

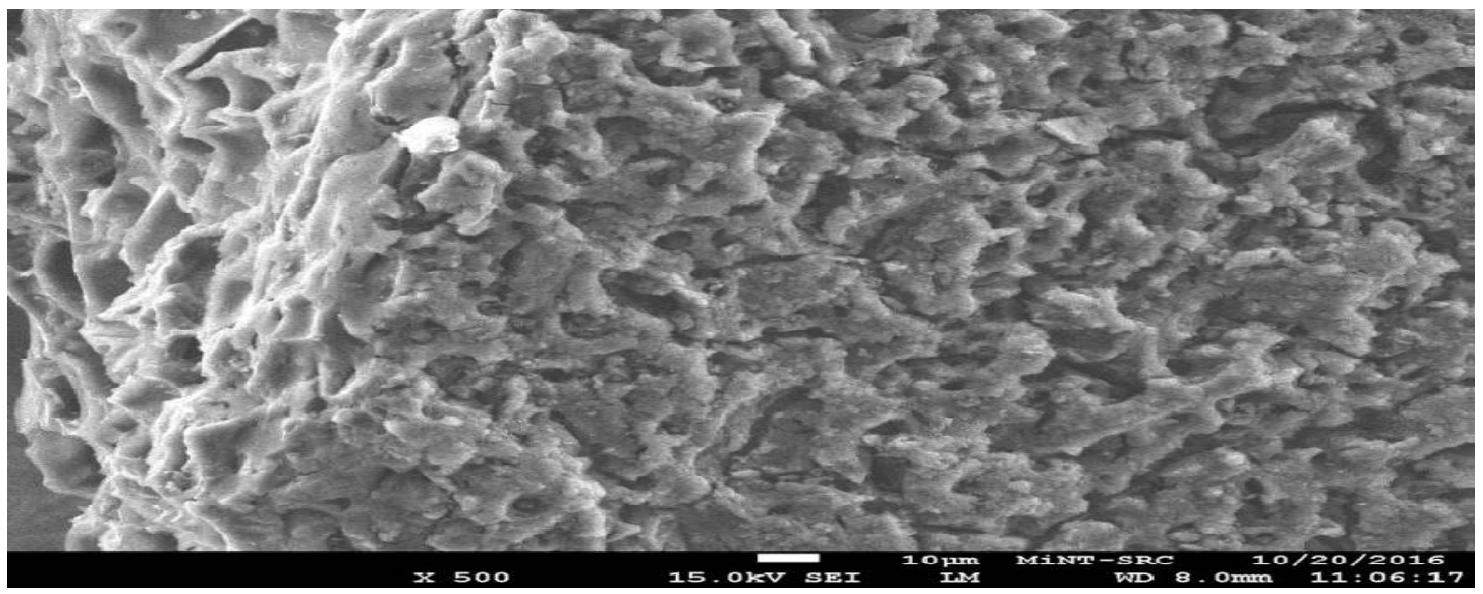

(b) Magnification 500x

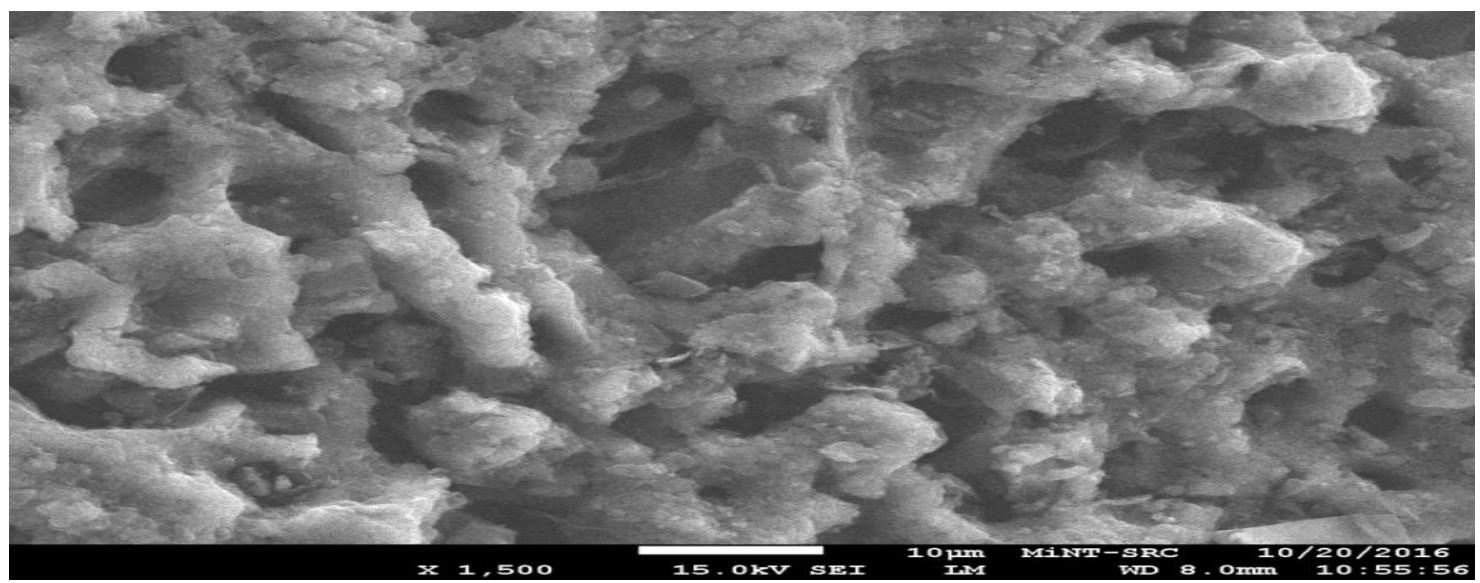

(c) Magnification $1.5 \mathrm{Kx}$

Fig.3. FESEM micrographs of prepared activated carbon, TSC at different magnification (a) $35 \mathrm{x}$, (b) $500 \mathrm{x}$ and (c) $1.5 \mathrm{Kx}$ respectively 


\subsubsection{Nitrogen Gas Adsorption Single Point Analysis}

In this study, the surface characteristic which is the surface area of the prepared sample TSC activated carbon was obtained. The BET surface area $\left(\mathrm{S}_{\mathrm{BET}}\right)$ of TSC was carried out by using Single Point Nitrogen $\left(\mathrm{N}_{2}\right)$ adsorption analysis using $77 \mathrm{~K}$ surface area analyzer and the results obtained were compared to other studies as in Table 1. The $\mathrm{S}_{\mathrm{BET}}$ result obtained was 594.04 $\mathrm{m}^{2} \mathrm{~g}^{-1}$ which is greater compared to other studies. Previous studies showed that tamarind seed activated with potassium hydroxide $(\mathrm{KOH})$ and without any activation agent gave a very low or small surface area, $\mathrm{S}_{\mathrm{BET}}$ which were $2.7167 \mathrm{~m}^{2} \mathrm{~g}^{-1}$ and $0.99 \mathrm{~m}^{2} \mathrm{~g}^{-1}$ respectively [17-18]. This is maybe because the pores were not properly developed during the preparation process. However, the use of phosphoric acid $\left(\mathrm{H}_{3} \mathrm{PO}_{4}\right)$ as activating agent in the preparation steps shows it may help in created more pores in the prepared TSC thus directly increased the surface area.

Table 1. The comparison of surface area $\left(\mathrm{S}_{\mathrm{BET}}\right)$ of the activated carbon from tamarind seed

\begin{tabular}{ccc}
\hline Type of Sample/Activating Agent & $\mathbf{S}_{\text {BET }}\left(\mathbf{m}^{\mathbf{2}} \mathbf{g}^{-\mathbf{1}}\right)$ & References \\
\hline Tamarind seed $/ \mathrm{H}_{3} \mathrm{PO}_{4}$ & 594.04 & This study \\
Tamarind seed / $\mathrm{KOH}$ & 2.7167 & {$[19]$} \\
Tamarind seed / - & 0.99 & {$[20]$} \\
\hline
\end{tabular}

\subsection{Adsorption Solid-Liquid Analysis}

\subsubsection{Effect of Initial MB Concentration}

The effect of dye concentration was determined by the concentration of the MB in the range of $30 \mathrm{ppm}, 60 \mathrm{ppm}, 90 \mathrm{ppm}, 120 \mathrm{ppm}$ and $150 \mathrm{ppm}$. The results of the adsorption capacity of the MB onto the prepared activated carbon, TSC recorded are shown in Table 2. From the data in Table 2, it shows that the adsorption capacity, $q_{e}$ wereincreased in the MB concentrations from $30 \mathrm{ppm}$ to $120 \mathrm{ppm}$. The adsorption percentage was increased from $77 \%$ to $87 \%$. However, adsorption capacity of MB was decreased at $150 \mathrm{ppm}$. The concentration of the MB after the adsorption was in the range of between $22.86 \mathrm{ppm}$ to $102.76 \mathrm{ppm}$. This situation can be explained as the higher the concentrations of $\mathrm{MB}$ are the more $\mathrm{MB}$ ions were adsorbed on the pores of the surface of the adsorbent, TSC. The data obtained shows at low concentration up to $120 \mathrm{ppm}, 0.04 \mathrm{~g}$ TSC may possible to adsorb MB up to $87 \%$ because of the much surface area are available to be filled by MB. In contrast, the adsorption capacity was 
decreased at $150 \mathrm{ppm}$ shows that may be the adsorption sites of TSC were saturated with MB and the adsorbate cannot fit in the pore size hence reduced the adsorption percentage. Thus, the highest concentration that can be adsorbed by $0.04 \mathrm{~g}$ TSC was $120 \mathrm{ppm}$.

Table 2. Adsorption capacity of MB onto TSC in different concentration by $0.04 \mathrm{~g}$ of TSC at temperature $323 \mathrm{~K}$

\begin{tabular}{ccc}
\hline Concentration (ppm) & Adsorption Capacity, $\mathbf{q}_{\mathbf{e}}(\mathbf{x} / \mathbf{m})$ & Adsorption Percentage (\%) \\
\hline 30 & 22.86 & 77.87 \\
60 & 45.63 & 79.55 \\
90 & 73.14 & 83.10 \\
120 & 102.76 & 87.35 \\
150 & 98.75 & 86.15
\end{tabular}

Furthermore, the adsorption percentage increased from $77 \%$ to $87 \%$ which shows that the rate of removal of the dye is faster at lower concentration and decreased with increasing concentration [19]. Again, this may be caused by the adsorption into the pores on the surface of TSC that was not saturated yet and therefore, the removal percentage of MB by TSC showed an increased trend.This study showed that the concentration of the adsorbate (MB) can affect the adsorption process onto the prepared activated carbon, TSC.

\subsubsection{Effect of Temperature}

The adsorption process was done at the temperature of $303 \mathrm{~K}, 313 \mathrm{~K}, 323 \mathrm{~K}$ and $333 \mathrm{~K}$ for two hours with highest concentration which was $120 \mathrm{ppm}$. The adsorption capacity of MB onto TSC for the different temperature is shown in Table 3. Table 3 shows that the adsorption percentages of $\mathrm{MB}$ were $81 \%, 86 \%, 87 \%$ and $83 \%$ for temperature $303 \mathrm{~K}, 313 \mathrm{~K}, 323 \mathrm{~K}$ and $333 \mathrm{~K}$ respectively. The adsorption capacity $\left(\mathrm{q}_{\mathrm{e}}\right)$ was increased from $96 \mathrm{mg} / \mathrm{g}$ to $102 \mathrm{mg} / \mathrm{g}$ when the temperature was increased from $303 \mathrm{~K}$ to $323 \mathrm{~K}$. The increased temperatures greatly raise the adsorption capacity of MB. This study indicated that the increasing temperature up to $323 \mathrm{~K}$ was suitable for the adsorption of MB onto TSC maybe because the MB particles were gained maximum energy to move and adsorb on the surface of TSC. Thus, more MB particles have been removed by TSC activated carbon. However, the adsorption capacity of MB was decreased at temperature $333 \mathrm{~K}$. This might be because the pores of TSC were destructed and loss the ability to have interaction with MB particles and lead to less adsorption capacity [20]. In addition, the adsorption percentage of MB onto TSC for both adsorption studies were high 
which almost reached $90 \%$ shows that the prepared activated carbon, TSC has a potential to be used as an adsorbent in the future.

Table 3. Adsorption capacity of MB onto TSC in different temperature at $120 \mathrm{ppm}$ by $0.04 \mathrm{~g}$ of TSC

\begin{tabular}{ccc}
\hline Temperature (K) & Adsorption Capacity, $\mathbf{q}_{\mathbf{e}}(\mathbf{x} / \mathbf{m})$ & Adsorption Percentage (\%) \\
\hline 303 & 95.99 & 81.76 \\
313 & 98.61 & 86.76 \\
323 & 102.77 & 87.35 \\
333 & 99.77 & 83.65 \\
\hline
\end{tabular}

\section{EXPERIMENTAL}

\subsection{Preparation of TSC Activated Carbon}

$100 \mathrm{~g}$ of tamarind seeds was washed thoroughly under running tap water to remove dust and any undesirable particles. The preparations of the activated carbon were carried out by using the chemical activation method. The chemical activation was accomplished by using a two-step method which was pre-treatment and impregnated processes. Phosphoric acid $\left(\mathrm{H}_{3} \mathrm{PO}_{4}\right)$ was used as an activating agent [16]. For pre-treatment process, the tamarind seeds were treated with $30 \%$ of $\mathrm{H}_{3} \mathrm{PO}_{4}$ for four hours and the samples were dried by using an oven at $110{ }^{\circ} \mathrm{C}$. Next, the pre-activate tamarind seeds were impregnated with a high concentration activating agent, $50 \mathrm{~mL}$ of $85 \%$ of phosphoric acid, $\mathrm{H}_{3} \mathrm{PO}_{4}$ with a ratio of phosphoric acid: deionized water as 1: 1 . The tamarind seeds were soaked with the activating agent for 20 hours and before activating, the samples were made sure to be in a semidried condition. Then, the samples underwent the activation process at $500{ }^{\circ} \mathrm{C}$ for four hours in muffle furnace to remove the non-carbonaceous components [21]. Lastly, the samples was washed with deionized water and $1.0 \mathrm{M}$ of sodium hydroxide $(\mathrm{NaOH})$ using vacuum filtration until the $\mathrm{pH}$ of the sample is neutral [22]. Thus, the prepared activated carbon was named as a tamarind seed carbon (TSC) that was used as adsorbent in this study.

\subsection{Characterization of TSC Activated Carbon}

The prepared activated carbon TSC was characterized for the physical and chemical properties by using the Fourier Transformed Infrared Spectroscopy (FTIR) (PerkinElmer Spectrum 100) 
to determine the presence of the functional groups in the TSC within the range of between 4000 $\mathrm{cm}^{-1}$ to $400 \mathrm{~cm}^{-1}$. Surface morphology and porosity of prepared TSC was analyzed by Scanning Electron Microscopy (FESEM) (JEOL JSM 7500F) and surface area of TSC was determine by Single Point Nitrogen $\left(\mathrm{N}_{2}\right)$ adsorption analysis using $77 \mathrm{~K}$ surface area analyzer (Micromeritics ASAP 2010).

\subsection{Adsorption Solid-Liquid Analysis}

\subsubsection{Preparation of Methylene Blue (MB) Dye}

Synthetic MB dye from R\&M Chemicals was used as adsorbate and all solutions were prepared with double distilled deionized water $18 \mathrm{M} \Omega$ purified by Nano Ultra-Pure Water System (Barnstead, USA). Molecular structure of MB as shown in Fig. 4. 1000 ppm stock solution of MB was prepared by dissolving $0.5000 \mathrm{~g}$ of MB in $500 \mathrm{~mL}$ volumetric flask.<smiles>CN(C)c1ccc2nc3ccc(=[N+](C)C)cc-3sc2c1</smiles>

Fig.4. Molecular structure of MB

\subsubsection{Adsorption Studies-Effect of Concentration and Temperature}

The optimization conditions were done to determine the equilibrium adsorption studies of $\mathrm{MB}$ into prepared TSC which are concentration and temperature. The effect of concentration was studied by preparing a series of dilution concentration from the stock solution (1000 ppm). A series of MB aliquots with 30 ppm, 60 ppm, 90 ppm, 120 ppm and $150 \mathrm{ppm}$ concentration were prepared in $50 \mathrm{~mL}$ volumetric flask respectively. $0.04 \mathrm{~g}$ of TSC was added into four Erlenmeyer flasks and each concentration of MB solution was pipetted into each Erlenmeyer flask respectively. The Erlenmeyer flasks were wrapped with parafilm and placed in the electronic water bath shaker. The solutions were shaken at constant a speed of $160 \mathrm{rpm}$ at $303 \mathrm{~K}$ for two hours. After that, the TSC samples were filtered using filter papers. The filtrates of MB obtained were analyzed by using T80+ UV/Visible spectrometer at $667.5 \mathrm{~nm}$ as the maximum wavelength. Then, the amounts of $\mathrm{MB}$ adsorption capacities $\mathrm{q}_{\mathrm{e}}$ were calculated using Equation (1).

$$
q_{e}=\frac{(C o-C e) V}{W}
$$


Based on Equation (1), $\mathrm{C}_{\mathrm{o}}$ and $\mathrm{C}_{\mathrm{e}}\left(\mathrm{mg} \mathrm{L}^{-1}\right)$ are the liquid phase concentrations of $\mathrm{MB}$ at initial and at equilibrium respectively. $\mathrm{W}$ is the weight of the adsorbent (TSC activated carbon) used in gram (g) and V is the volume of the solution in liter $(\mathrm{L})$. The same procedure was followed to study the effect of temperature of MB into TSC activated carbon. The temperatures that were conducted subsequently were $313 \mathrm{~K}, 323 \mathrm{~K}$, and $333 \mathrm{~K}$ respectively. The concentration of MB that was used was $120 \mathrm{ppm}$ as the optimum concentration. All experiments were conducted triplicate under identical conditions [14].

\section{CONCLUSION}

As a conclusion, the removal of dye which is methylene blue (MB) by the adsorption process from the prepared activated carbon, Tamarindusindica(tamarind seeds activated carbon, TSC) show better results. The conditions used to prepare activated carbon TSC by using the $\mathrm{H}_{3} \mathrm{PO}_{4}$ as an activating agent using impregnation ratio (1:1) at temperature $500{ }^{\circ} \mathrm{C}$ for four hours was enhanced the surface area $\left(\mathrm{S}_{\mathrm{BET}}\right)$ obtained. FTIR analysis was provided an evidence that there are no functional groups present on the TSC surface, which can be assumed that TSC also might also have the capacity to be used as an adsorbent as CAC. The best conditions for TSC to adsorb $\mathrm{MB}$ effectively were at $50 \mathrm{~mL}$ of $\mathrm{MB}$ with concentration $120 \mathrm{ppm}$ at temperature, $323 \mathrm{~K}$ by using $0.04 \mathrm{~g}$ of TSC activated carbon. The maximum adsorption capacity for MB dye solution was $102.77 \mathrm{mg} \mathrm{g}^{-1}$.

\section{ACKNOWLEDGEMENTS}

The authors would like to extend their sincere appreciation to the Research Department Chemistry Final Year Project Laboratory, Faculty of Applied Sciences, UiTM Kuala Pilah and Microelectronic and Nanotechnology Shamsuddin Research Centre (MiNT-SRC) of UniversitiTun Hussein Onn Malaysia for the facilities provided.

\section{REFERENCES}

[1] Ngulube T, Gumbo J R, Masindi V, Maity A. An update on synthetic dyes adsorption onto clay based minerals: A state-of-art review. Journal of Environmental Management, 2017, $191: 35-57$ 
[2] Rajeswari A, Vismaiya S, Pius A. Preparation, characterization of nanoZnO-blended cellulose acetate-polyurethane membrane for photocatalytic degradation of dyes from water. Chemical Engineering Journal, 2017, 313:928-937

[3] Zuraida S, NurhaslinaC, Hamid K H. Removal of synthetic dyes from wastewater by using bacteria, lactobacillus delbruckii.International Refereed Journal of Engineering and Science, 2013, 2(5):1-7

[4] Wong Y C, Senan M S, Atiqah N A. Removal of methylene blue and malachite green dye using different form of coconut fibre as absorbent. Journal of Basic and Applied Sciences, 2013, 9:172-177

[5] Menzies T, Raffo D, Setamanit S O, Hu Y, Tootoonian S. Model-based tests of truisms. In 17th IEEE International Conference on Automated Software Engineering, 2002, pp. 183-191

[6] Tharaneedhar V, Kumar P S, Saravanan A, Ravikumar C, Jaikumar V. Prediction and interpretation of adsorption parameters for the sequestration of methylene blue dye from aqueous solution using microwave assisted corncob activated carbon. Sustainable Materials and Technologies, 2017, 11:1-11

[7] Ezechi E H, Mohamed K S R, Malakahmad A, Isa M H. Characterization and optimization of effluent dye removal using a new low cost adsorbent: Equilibrium, kinetics and thermodynamic study. Process Safety and Environmental Protection, 2015, 98:16-32

[8] Shi Q, Zhang J, Zhang C, Li C, Zhang B, Hu W, Xu J, Zhao R. Preparation of activated carbon from cattail and its application for dyes removal. Journal of Environmental Sciences, 2010, 22(1):91-97

[9] Hidayu A R, Muda N. Preparation and characterization of impregnated activated carbon from palm kernel shell and coconut shell for $\mathrm{CO}_{2}$ capture. Procedia Engineering, 2016, 148:106-113

[10] Gupta S, Babu B V. Utilization of waste product (tamarind seeds) for the removal of Cr (VI) from aqueous solutions: equilibrium, kinetics, and regeneration studies. Journal of Environmental Management, 2009, 90(10):3013-3022

[11] Jellali S, Diamantopoulos E, Haddad K, Anane M, Durner W, Mlayah A. Lead removal from aqueous solutions by raw sawdust and magnesium pretreated biochar: Experimental investigations and numerical modelling. Journal of Environmental Management, 2016, 180:439-449

[12] Vasu A E. Removal of basic dyes from aqueous solutions by activated carbon prepared from Tamarindusindica fruit shells. Oriental Journal of Chemistry, 2008, 24(3):947-954 
[13] Gayathri R, Thirumarimurugan M, Kannadasan T. Removal of chromium (VI) ions from aqueous solution using tamarind seeds as an adsorbent.International Journal of Pharmaceutical and Chemical Sciences, 2013, 2(2):984-991

[14] Soleimani M. Low-cost adsorbents from agricultural by-products impregnated with phosphoric acid. Advanced Chemical Engineering Research, 2014, 3:34-39

[15] Hussain A., Saiyudi N. K. W. M. Introduction to surface and colloid chemistry. Johor: UniversitiTeknologi Malaysia, 2006

[16] Jamion B, Mohamed B, Mazleena S. Characterization of activated carbon from sugar cane husk. Applied Mechanics and Materials, 2014, 699:1006-1011

[17] Mopoung S, Moonsri P, Palas W, Khumpai S. Characterization and properties of activated carbon prepared from tamarind seeds by $\mathrm{KOH}$ activation for $\mathrm{Fe}$ (III) adsorption from aqueous solution. The Scientific World Journal, 2015, 2015:1-9

[18] Rajeshkannan R, Rajasimman M, Rajamohan N. Decolourization of malachite green using tamarind seed: Optimization, isotherm and kinetic studies. Chemical Industry and Chemical Engineering Quarterly, 2011, 17(1):67-79

[19] Tan I A, Hameed B H, Ahmad A L. Equilibrium and kinetic studies on basic dye adsorption by oil palm fibre activated carbon. Chemical Engineering Journal, 2007, 127(1):111-119

[20] Ngadi N, EeC C, Yusof N A. Removal of methylene blue dye by using eggshell powder. JurnalTeknologi, 2013, 651(1):63-71

[21] Phatai P, Klinkaewnarong J, Yaiyen S. Adsorption of methyl violet dye from aqueous solutions by activated carbon produced from tamarind seeds. Advanced Materials Research, 2014, 911:326-330

[22] Gad H M, El-Dessouky S I, Daifullah A A. A study of the factors affecting the removal of lanthanides from nitrate solution by activated carbon prepared from date pits. International Journal of Environmental Engineering Science, 2011, 2(1):29-50

\section{How to cite this article:}

Jamion N. A, Hashim I. N, Reparation of activated carbon from tamarind seeds and methylene blue (MB) removal. J. Fundam. Appl. Sci., 2017, 9(6S), 102-114. 